\title{
Sotos' Syndrome (Cerebral Gigantism) with Peripheral Dysostosis
}

\author{
P. R. EVANS \\ From The Hospital for Sick Children, Great Ormond Street, London
}

\begin{abstract}
Evans, P. R. (1971). Archives of Disease in Childhood, 46, 199. Sotos' syndrome (cerebral gigantism) with peripheral dysostosis. A girl had short stumpy hands and feet due to osseous dystrophy; in other respects she showed all the main and many of the minor features of Sotos' syndrome during infancy. Then she was on the 97th centile for height, but she grew to be a woman on the 10th centile. Menarche was at $12 \frac{3}{4}$ years; growth in height stopped before $14 \frac{1}{2}$ though epiphysial fusion had not occurred; educational difficulties were still being fought at 18 years but she was well adjusted and happy.
\end{abstract}

This case is presented because (1) the combination of cerebral gigantism and gross manupedal dysostosis is unusual, perhaps unique; and (2) growth has been followed from infancy into adult life.

\section{Case Report}

The patient was a girl born in 1952, only child of non-consanguineous parents; her father was an epileptic house-painter taking phenobarbitone. Pregnancy and delivery were normal, birthweight was $2270 \mathrm{~g}$; she was given oxygen for one week and kept in hospital for one month. She was breast-fed for 8 months, got her first tooth at 6 months, sat and stood normally, walked at 18 months, spoke her first word at 2 years; sphincter control was normal.

She was brought to hospital at 3 years because of

Received 10 September 1970. clumsiness of hands and tendency to run on toes instead of walking, to trip and to fall forward. She was a tall, long-legged, heavy girl with rosy cheeks: upper to lower segment ratio was 1.16 (average for age 1.35 , for height 1.24); span was $96.5 \mathrm{~cm}$ (average $90.5 \mathrm{~cm}$ for age, $99 \mathrm{~cm}$ for height); head circumference was $53 \mathrm{~cm}$ (average for age $51 \mathrm{~cm}$ ), chest circumference was $58 \mathrm{~cm}$. Hands and feet were broad (Fig. 1a). She had 17 teeth, 3 more had been removed for caries. She had a depressed nasal bridge and a staring expression (Fig. 2a). Tonsils were infected. BP $120 / 80 \mathrm{~mm} \mathrm{Hg}$. Speech was indistinct, perhaps in part due to a hearing loss of 10-20 decibels at $250-4000$ c.p.s. The following results were normal: nuclear sexing of leucocytes; glucose tolerance test; subcutaneous insulin sensitivity test; blood plasma levels of bicarbonate, $\mathrm{Na}, \mathrm{Cl}, \mathrm{K}, \mathrm{Ca}, \mathrm{P}$, alkaline phosphatase, free and ester cholesterol; urinary secretion in 24 hours of 17 ketosteroids and 17 hydroxicorticoids; urea clearance; radiographs of skull,

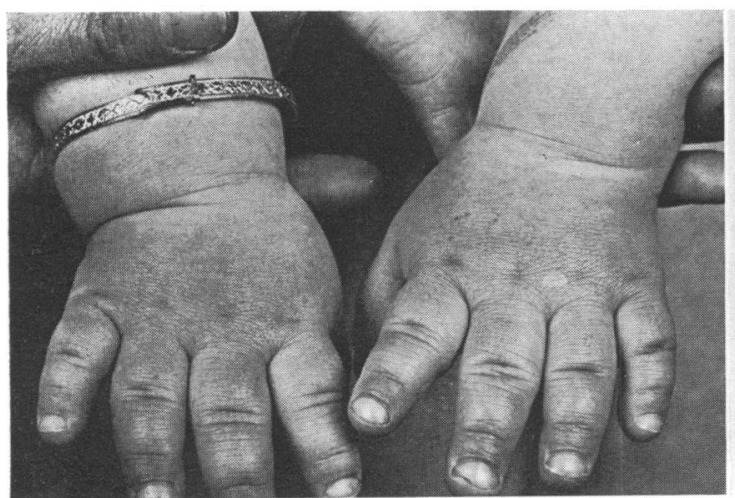

(a)

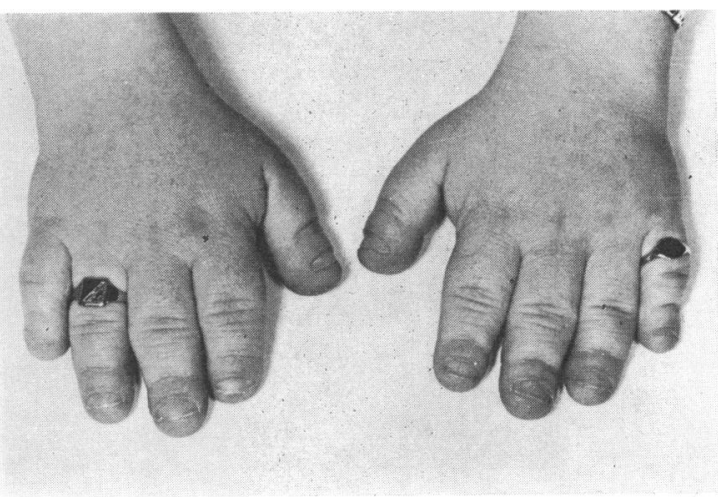

(b)

FIG. 1.-Patient (a) hands at 3 years; (b) hands at 17 years; they look as immature as at the age of 3 years. 


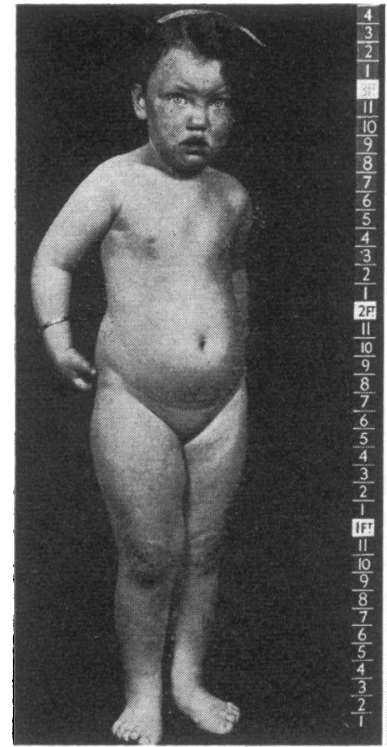

(a)

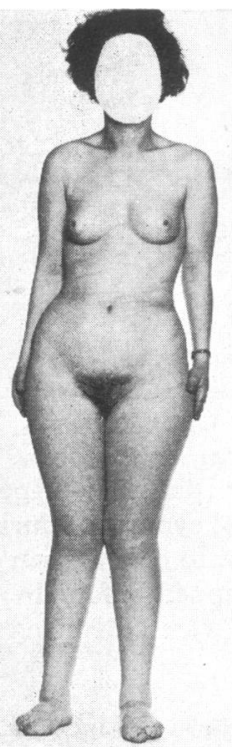

(b)
Frg. 2.-(a) At 3 years. (b) At 17 years. The face (deleted) has matured, corresponding to her age.

spine, and chest. Metatarsals, metacarpals, and phalanges were short and wide (Fig. 3a), with cupped ends and no calcified epiphyses, yet the carpus was like that of a child twice her age.

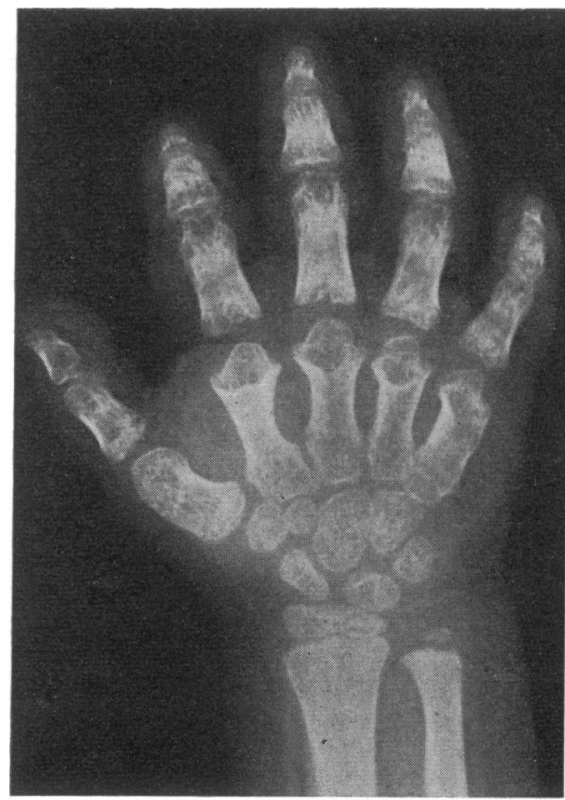

Fig. 3.-(a) X-ray of hand at 3 years. $\stackrel{(a)}{(b)} X$-ray at 18 years. Ulnar and radial epiphyses have not fused, while metacarpal,

At 5 years, tonsils and adenoids were removed. At 6 years, IQ was estimated as 89 . At 10 years, she transferred to a school for educationally subnormal children as she had poor auditory discrimination and was clumsy. At 12 years, the pituitary fossa was examined radiographically because of the possibility of acromegaly, but it was normal; the vault of the skull was thick. There was valgus deformity of the feet, varus of the ankles, and dental caries was evident. At $12 \frac{3}{4}$ years she first menstruated. At 13 years, a mixed parotid tumour was excised. EEG showed increased delta activity and some symmetrical following under photostimulation, with a resting record of 4-8 c.p.s., and there was high voltage activity with underlying low voltage activity without focal features. At 14 years, shoes were $22 \mathrm{~cm}$ long and $11 \mathrm{~cm}$ wide; shoulder movements were stiff so that she could not undo her dress at the back. When last seen at 17 years she was a healthy, happy girl, short in stature but not abnormally so, large of hip and thigh compared with chest and shoulder (Fig. 2b). She was still learning 'reading and writing and arithmetic' at evening school-her writing was like that of a child 10 years younger, and she was not very good at spelling or sums involving pounds, shillings, and pence. She had compensated well for her earlier clumsiness and was doing fine work as a Quick-unpick assembler (Quick-unpick unpicks hems). She could not pick small objects up from a flat surface but when asked to take a pin from a hard table, she neatly swept it to the edge where her stubby fingers were able to close over it as it turned the corner. She was waiting for a plastic operation to construct a bridge in her nose as her

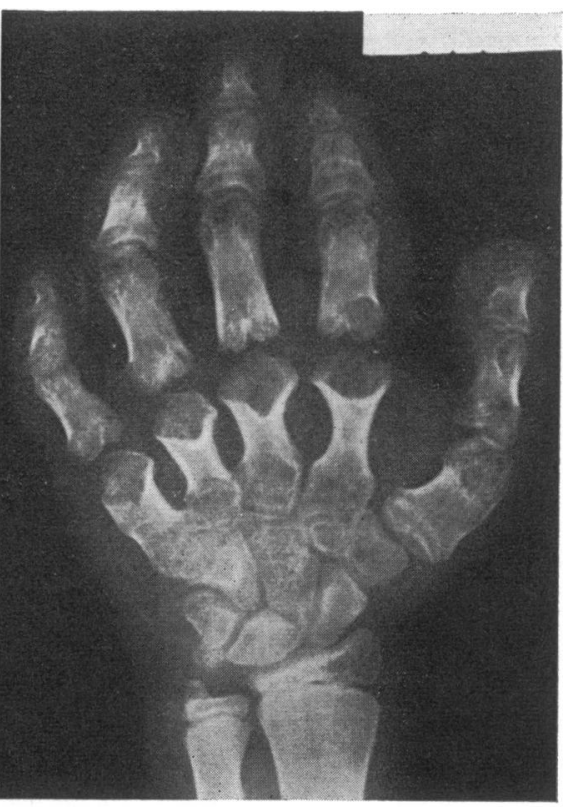
and phalangeal epiphyses have not even appeared. 
spectacles (she was myopic) slid down. She still needed special shoes; her hands (Fig. 1b) and feet looked much as before with gross valgus of the big toes and valgus knees. There was some acne; breasts were of ordinary size but nipples were small, menstrual flow continued for 7 days every 3 to 4 weeks. Upper/lower segment ratio was 1.1 (average for age 1.01 ); span $137 \mathrm{~cm}$ (average for age $165 \mathrm{~cm}$ ); head circumference $59 \mathrm{~cm}$ (average $56 \mathrm{~cm}$ ). Epiphysial fusion was delayed (Fig. 3b).

\section{Discussion}

'Cerebral gigantism' is a term introduced by Sotos et al. (1964). 'Sotos' syndrome consists of 'excessively rapid growth dating from infancy, acromegalic features and a non-progressive neurological disorder manifested by clumsiness and a dull intelligence' (Abraham and Snodgrass, 1969). The definition fits this case except that the hands (Fig. 1) and feet were short, i.e. there was no acromegaly; her facial appearance (Fig. 2a) resem-

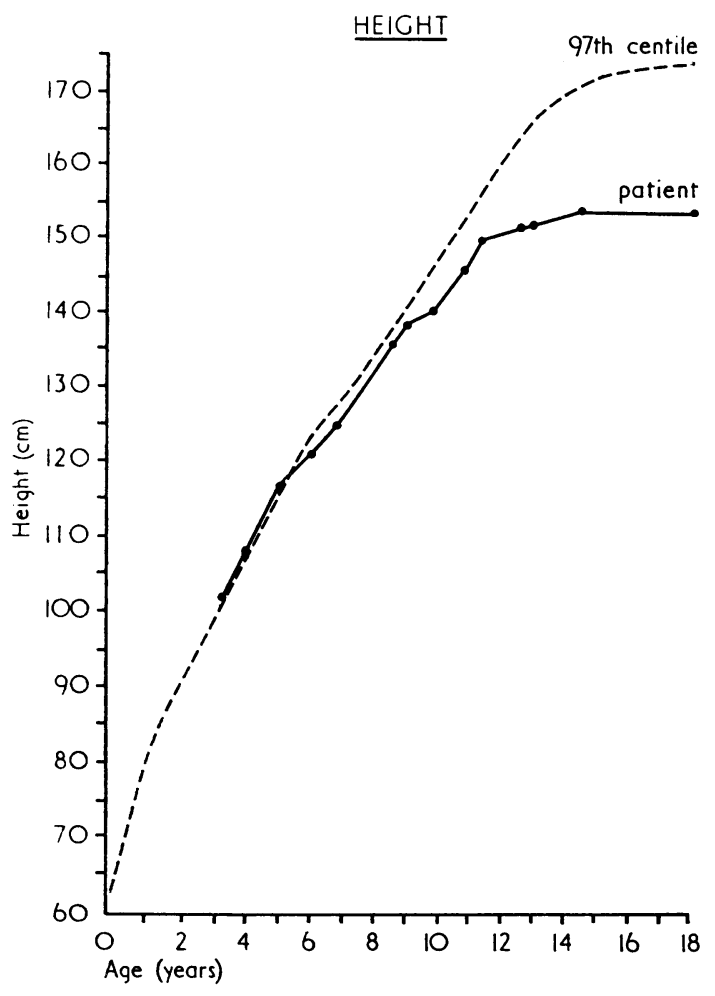

(a) bles that seen in the cases of Abraham and Snodgrass (1969).

The dysostosis occurring in this case (Fig. 3 and 4) is more difficult to name, but Dr. A. R. Chrispin has pointed out that it is similar to the 'peripheral dysostosis' described by Garces et al. (1969). The patients described by Sotos et al. (1964) showed advanced bone age, large hands and feet, and slight tufting of terminal phalanges in 2 patients out of 5 , but no gross abnormality.

These authors described very rapid growth in the first 4 years of life, followed by growth parallel to the normal curve. Gigantism is perhaps too big a word, but they certainly are large children, usually around the 97th centile in height. In the patient described here height was first recorded at 3 years, it remained at the 97th centile until the age of 10 years, but increased little after that (Fig. 4a). Adult height had been reached by $14 \frac{1}{2}$ years, and was on the 10th centile, a paradoxical swing from the giant infant to the little woman. Weight followed a comparable course (Fig. 4b) allowing for her being a fat child.

Abraham and Snodgrass (1969) note features reported in accounts of 43 cases of Sotos' syndrome; of those occurring in a third or more the following were present in this case: birth at term, neonatal respiratory difficulty, delayed walking, delayed speech, IQ below 90, macrocrania, hypertelorism (probably), antimongoloid slant of eyes, facial plethora, prognathism, clumsiness, abnormal EEG, normal pituitary fossa. Missing features were: high birthweight, jaundice, feeding problems,

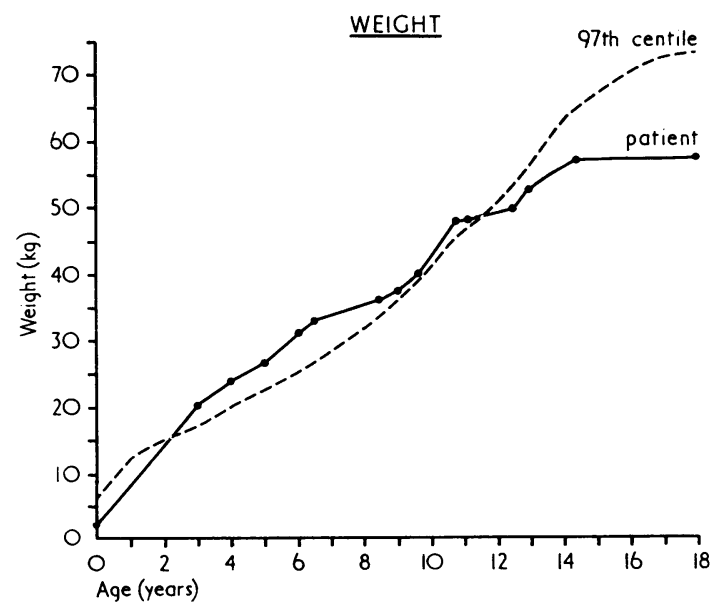

(b)

FIG. 4.-(a) Height of patient from the third to the eighteenth year, compared with 97th centile. (b) Weight of patient from the third to the eighteenth year, compared with 97th centile. 
aggressiveness, kyphosis or scoliosis, large hands and feet, convulsions, drooling, and high 17ketosteroids.

\section{REFERENCES}

Abraham, J. M., and Snodgrass, G. J. A. I. (1969). Sotos' syndrome of cerebral gigantism. Archives of Disease in Childhood, 44, 203.

Garces, L. Y., Blank, E., Drash, A. L., and Kenny, F. M. (1969)

Peripheral dysostosis: investigation of metabolic and endocrine functions. Fournal of Pediatrics, 74, 730.
Sotos, J. F., Dodge, P. R., Muirhead, D., Crawford, J, D, and Talbot, N. B. (1964). Cerebral gigantism in childhood: a syndrome of excessively rapid growth with acromegalic features and a nonprogressive neurologic disorder. New England fournal of Medicine, 271, 109.

Correspondence to Dr. P. R. Evans, Guy's Hospital, St. Thomas's Street, Lonaon S.E.1. 